\title{
Article \\ Nasal Delivery of Cinnarizine Thermo- and Ion-Sensitive In Situ Hydrogels for Treatment of Microwave-Induced Brain Injury
}

\author{
Yuanyuan Zhang ${ }^{1,2}$, Qian Li ${ }^{1,2}$, Jinglu $\mathrm{Hu}^{2,3}$, Chunqing Wang ${ }^{1,2}$, Delian Wan ${ }^{1,2}$, Qi Li ${ }^{1,2}$, Qingwei Jiang ${ }^{4, *}$, \\ Lina $\mathrm{Du}^{1,2,3, * \mathbb{B}}$ and Yiguang Jin 2,3 \\ 1 School of Pharmacy, Shandong University of Traditional Chinese Medicine, Jinan 250355, China; \\ 17853464723@163.com (Y.Z.); 17862969577@163.com (Q.L.); wcq19960911@163.com (C.W.); \\ delian169@163.com (D.W.); qili1029@163.com (Q.L.) \\ 2 Department of Pharmaceutical Sciences, Beijing Institute of Radiation Medicine, Beijing 100850, China; \\ hujinglu187@163.com (J.H.); jinyg@bmi.ac.cn (Y.J.) \\ 3 School of Pharmacy, Henan University, Kaifeng 475004, China \\ 4 Key Laboratory of Natural Medicine of the Changbai Mountain, Ministry of Education, College of Pharmacy, \\ Yanbian University, Yanji 133002, China \\ * Correspondence: qingwei_j@126.com (Q.J.); dulina@188.com (L.D.)
}

check for

updates

Citation: Zhang, Y.; Li, Q.; Hu, J.;

Wang, C.; Wan, D.; Li, Q.; Jiang, Q.;

Du, L.; Jin, Y. Nasal Delivery of

Cinnarizine Thermo- and

Ion-Sensitive In Situ Hydrogels for

Treatment of Microwave-Induced

Brain Injury. Gels 2022, 8, 108 .

https://doi.org/10.3390/

gels8020108

Academic Editor: Damien Dupin

Received: 11 January 2022

Accepted: 8 February 2022

Published: 10 February 2022

Publisher's Note: MDPI stays neutral with regard to jurisdictional claims in published maps and institutional affiliations.

Copyright: (C) 2022 by the authors. Licensee MDPI, Basel, Switzerland. This article is an open access article distributed under the terms and conditions of the Creative Commons Attribution (CC BY) license (https:// creativecommons.org/licenses/by/ $4.0 /)$.

\begin{abstract}
Background: When the body is exposed to microwave radiation, the brain is more susceptible to damage than other organs. However, few effective drugs are available for the treatment of microwave-induced brain injury (MIBI) because most drugs are difficult to cross the blood-brain barrier (BBB) to reach the brain. (2) Methods: Nasal cinnarizine inclusion complexes with thermo-and ion-sensitive hydrogels (cinnarizine ISGs) were prepared to treat MIBI and the characteristics of the inclusion complexes and their thermo-and ion-sensitive hydrogels were evaluated. (3) Results: Due to high viscosity, cinnarizine ISGs can achieve long-term retention in the nasal cavity to achieve a sustained release effect. Compared with the model, the intranasal thermo-and ion-sensitive cinnarizine ISGs significantly improved the microwave-induced spatial memory and spontaneous exploration behavior with Morris water maze and open field tests. Cinnarizine ISGs inhibited the expression of calcineurin and calpain 1 in the brain, which may be related to the inhibition of calcium overload by cinnarizine. (4) Conclusion: Intranasal thermo- and ion-sensitive cinnarizine ISGs are a promising brain-targeted pharmaceutical preparation against MIBI.
\end{abstract}

Keywords: microwave-induced brain injury (MIBI); cinnarizine; sulfobutyl- $\beta$-cyclodextrin; inclusion complex; thermo- and ion-sensitive hydrogels; brain targeting; intranasal administration

\section{Introduction}

Microwave radiation, which refers to electromagnetic waves with a frequency of $300 \mathrm{MHz}$ to $300 \mathrm{GHz}$, has various effects on many organs of the body, and the brain is generally considered to be the most susceptible organ for microwave radiation [1]. Operators who have been chronically exposed to microwave radiation will experience memory loss, headache, dreams, insomnia, and other symptoms [2-4]. The mechanisms of microwave radiationinduced brain injury remain unclear, possibly involving neuronal degeneration, apoptosis and necrosis, mitochondrial swelling and cavitation, reduction in Nissl bodies [5,6], destruction of the blood-brain barrier [7,8], synaptic structure and function of plastic damage [9], and calcium overload [10]. The current methods for protection against MIBI are mostly based on physical protection, such as protective clothing and protective helmets, with fewer therapeutic drugs. Kangfuling [11], Anduolin [12], and other traditional Chinese medicine compound oral preparations have systemic effects without brain specificity.

Normally, the extracellular free $\mathrm{Ca}^{2+}$ concentration is much higher than the intracellular concentration. After microwave radiation, the intracellular calcium ion content increases significantly, causing energy metabolism disorders and normal physiological 
processes $[13,14]$. Therefore, calcium channel blockers may become effective drugs for MIBI, with these including selective $\mathrm{Ca}^{2+}$ channel blockers, such as nifedipine, nimodipine, and diltiazem, and non-selective $\mathrm{Ca}^{2+}$ channel blockers, such as cinnarizine and flunarizine. These blockers are characterized by the ability to inhibit the influx of extracellular calcium ions by blocking the calcium ion channels on cell membranes so that the vascular smooth muscles can be relaxed, the peripheral vascular resistance reduced, and the pharmacological effect of lowering blood pressure achieved. These drugs are not only used for the treatment of high blood pressure clinically but they are also used for the treatment of coronary heart disease and angina pectoris [15]. There is the possibility that $\mathrm{Ca}^{2+}$ channel blockers can be used as promising therapeutic drugs against MIBI.

Cinnarizine is a well-known $\mathrm{Ca}^{2+}$ channel blocker; our previous research showed that cinnarizine had superiority in improving the spatial memory capacity of rats and reducing neuronal damage in the hippocampus of rats. However, it is a weakly alkaline drug that is only soluble in solutions with a $\mathrm{pH}$ value of 1 or less, and its solubility drops sharply in solutions with a $\mathrm{pH}$ value of 3 or higher, which leads to significant individual differences and poor bioavailability during clinical oral administration [16]. Cyclodextrin is characterized by the ability to increase the solubility of poorly soluble drugs in water and to improve the bioavailability, and sulfobutyl- $\beta$-cyclodextrin (SBE- $\beta-C D)$ has special affinity and inclusion characteristics for nitrogen-containing drugs.

Brain-targeted drug delivery is an important means by which to prevent and treat brain diseases through the BBB. Current intravenous injection methods involve the design of various nanoparticles that are complex and unsafe. Moreover, the drug dosage is restricted. All this poses an obstacle to simple or long-term use and to safe intracerebral drug delivery in case of MIRI. In situ hydrogels (ISGs) are fluid liquids without stimuli but they become semi-solid gels under the influence of some factors (such as temperature, $\mathrm{pH}$, and ions) after administration. After the stimulus is removed, they can reversibly return to the initial state [17-19]. In situ gel has many advantages, such as simple preparation, easy administration, good patient compliance, long local residence time, and low irritation. The nasal cavity has a large superficial area and rich capillaries where the temperature is maintained at about $35.5^{\circ} \mathrm{C}$ and the nasal fluid is rich in cations $\left(\mathrm{Na}^{+}, \mathrm{K}^{+}, \mathrm{Ca}^{2+}\right)[20]$, making it an ideal area for the administration of thermo- and ion-sensitive hydrogels. The unique trigeminal nerve and olfactory nerve pathways in the nasal cavity provide a new strategy for brain-targeted delivery.

Here, SBE- $\beta$-CD was used to prepare the cinnarizine inclusion complexes to improve its solubility and bioavailability before it was loaded into thermo- and ion-sensitive ISGs consisting of poloxamer 407 (P407) and deacetylated gellan gum (DGG) [21]. As the temperature rose, $\mathrm{P} 407$ molecules aggregated to form micelles, and more gelation occurred. Moreover, DGG combined potassium and calcium ions in the nasal fluid to form thermoand ion-sensitive ISGs that not only improved their bioavailability but could be administered through the nasal cavity to achieve brain targeting, whose MIBI pharmacodynamics were elucidated in an MIRI animal model.

\section{Results and Discussion}

\subsection{Formation of Cinnarizine Inclusion Complexes}

A phase solubility curve is often used to judge the inclusion ratios of drugs and cyclodextrins. The concentration of cinnarizine was positively correlated with the increase in SBE- $\beta$-CD concentration (Figure 1a). This was in line with the solubility diagram of the $A_{L}$ type phase, showing the formation of inclusion complexes at a 1:1 molar ratio [22,23] (Figure 1b). 
(a)

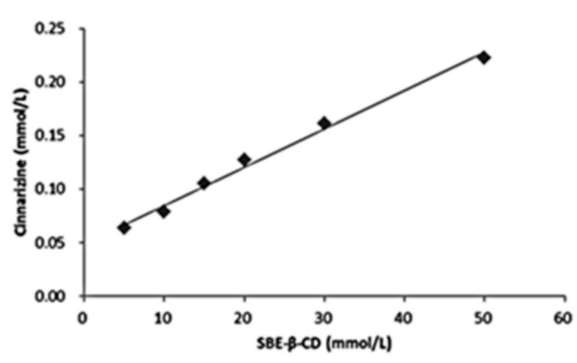

(b)

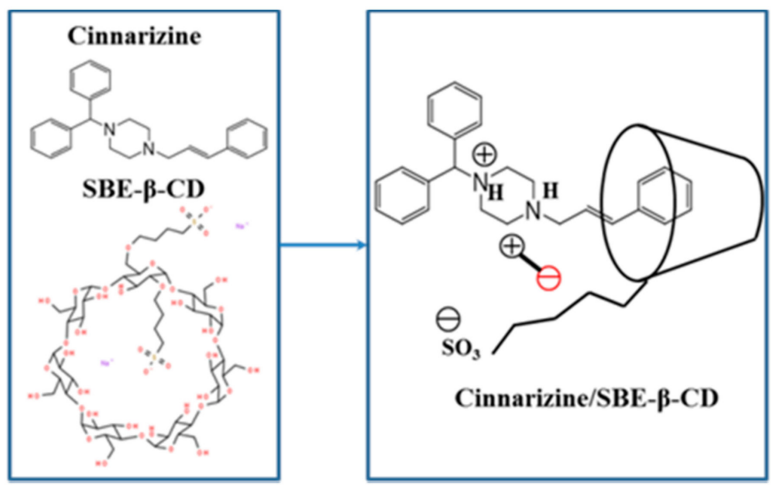

Figure 1. (a) Phase dissolution curves of cinnarizine and SBE- $\beta-C D$. (b) Inclusion mechanism of cinnarizine and SBE- $\beta-C D$.

We compared two methods of preparing cinnarizine inclusion complexes: grinding and freeze-drying. The water solubility of free cinnarizine was almost 0 , while the water solubility of the cinnarizine inclusion complexes prepared with the grinding and freezedrying methods was $4.10 \%(w / v)$ and $4.17 \%(w / v)$, respectively. Although their water solubility was similar, the preparation of the inclusion complexes by the freeze-drying method was relatively simple and not subject to human interference at an inclusion rate of $72.44 \%$.

Infrared (IR) spectroscopy can be used to determine whether the inclusion complexes are formed. The skeletal vibration of the benzene ring of cinnarizine was at 1596 and $1680 \mathrm{~cm}^{-1}$. The stretching vibration peak of the hydroxyl group of SBE- $\beta$-CD was at $3203 \mathrm{~cm}^{-1}$. In contrast, the IR spectrogram of the cinnarizine inclusion complexes was much similar to that of SBE- $\beta-C D$, with the hydroxyl group peak of $3219 \mathrm{~cm}^{-1}$. Meanwhile, the characteristic peak of the benzene ring of cinnarizine disappeared. It showed that cinnarizine had been completely encapsulated in the cavity of SBE- $\beta-C D$. The IR spectroscopy of the physical mixture of cinnarizine and SBE- $\beta-C D$ included both the characteristic peaks of cinnarizine and SBE- $\beta-C D$, which suggested that cinnarizine could not be trapped in the cavity of SBE- $\beta$-CD by straightforward physical blending (Figure 2a).

The peaks in the Differential Scanning Calorimeter (DSC) were also used to determine whether the inclusion complexes were formed. In the DSC curve, cinnarizine had a peak at $121{ }^{\circ} \mathrm{C}$, compared with $270{ }^{\circ} \mathrm{C}$ for SBE- $\beta-\mathrm{CD}$, which may be related to its thermal decomposition needing to absorb heat. There were small peaks of the physical mixture of cinnarizine and SBE- $\beta-\mathrm{CD}$ at 96 and $270{ }^{\circ} \mathrm{C}$; however, there were small peaks of cinnarizine inclusion complexes at 96 and $282{ }^{\circ} \mathrm{C}$. As the higher stability of the inclusion complex requires more heat to be absorbed for decomposition, the peak at around $270{ }^{\circ} \mathrm{C}$ was shifted to the right compared with the physical mixture (Figure $2 b$ ).

\subsection{Characteristics of Cinnarizine ISGs}

The P407 used in this research is a widely used thermo-sensitive polymer material, commonly used to prepare ISGs for the delivery of various drugs via ocular [24], nasal [25], vaginal [26], rectal [27], subcutaneous [28], topical [29], and intratumoral routes [30]. P407 has been approved by the FDA for ophthalmic or topical preparations due to its safety. Moreover, ISGs are used for stem cell therapy and regenerative medicine. The DGG solution can gel at a lower cation concentration because the cations can shield the electrostatic repulsion between the free carboxyl groups of DGG and improve the intermolecular cross bonding of DGG [31]. 


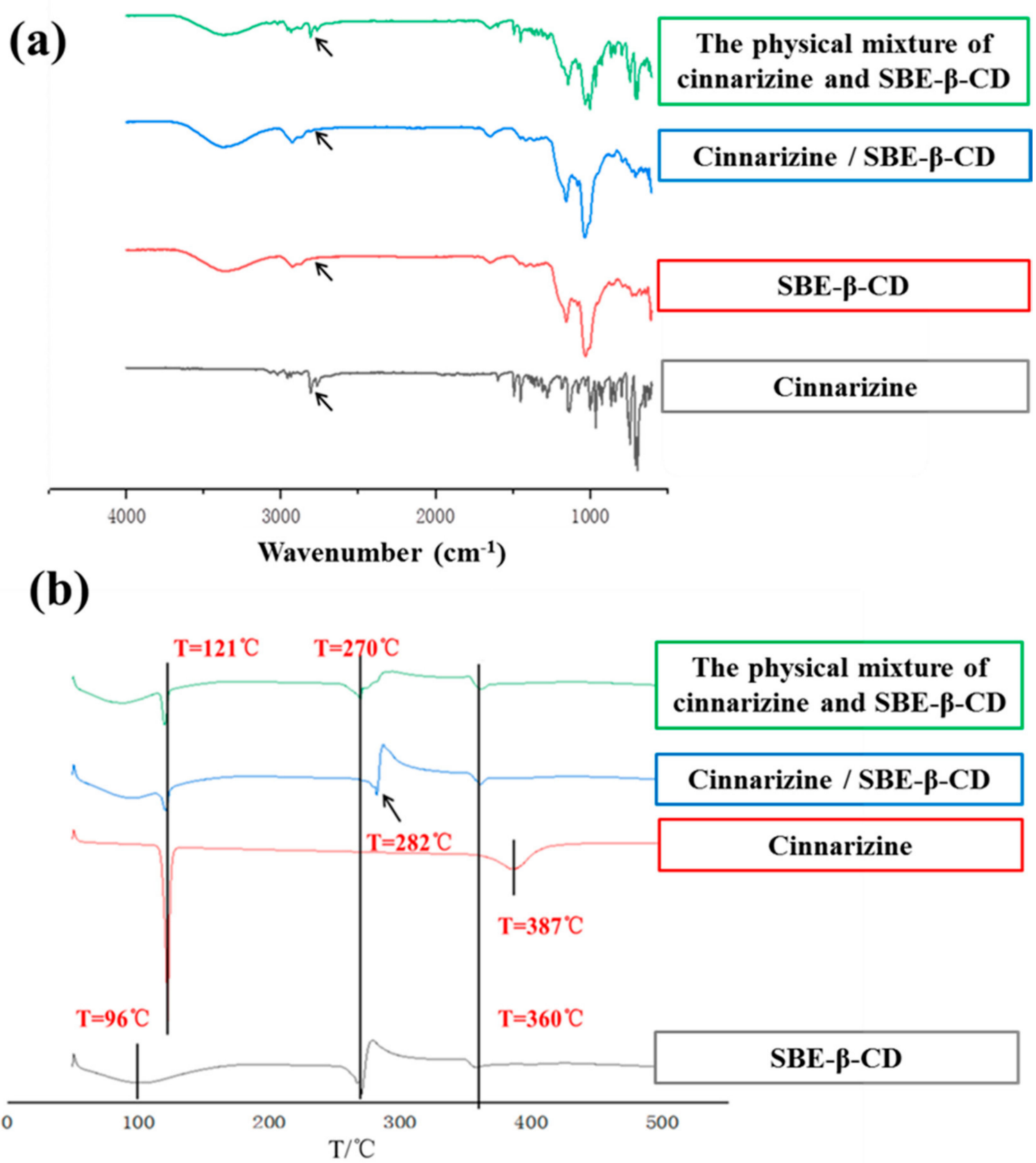

Figure 2. The infrared spectra (a) and DSC curves (b) of cinnarizine, SBE- $\beta-C D$, the cinnarizine SBE- $\beta$-CD inclusion complexes, and their physical mixture.

The viscosity of medicine is very important for nasal drug delivery systems and the appropriate viscosity of nasal preparations should be about 5.0 Pa.s [32]. The viscosity of ISGs containing 0.3\% (w/v) DGG and 17\% (w/v) P407 was $5.05 \mathrm{~Pa} \cdot \mathrm{s}$ at $37^{\circ} \mathrm{C}$ (Figure 3a), suitable for nasal drug delivery. The addition of $\mathrm{Ca}^{2+}, \mathrm{K}^{+}$and $\mathrm{Na}^{+}$improved the viscosity of the thermo- and ion-sensitive ISGs to $10.05 \mathrm{~Pa} \cdot \mathrm{s}$. 
(a)

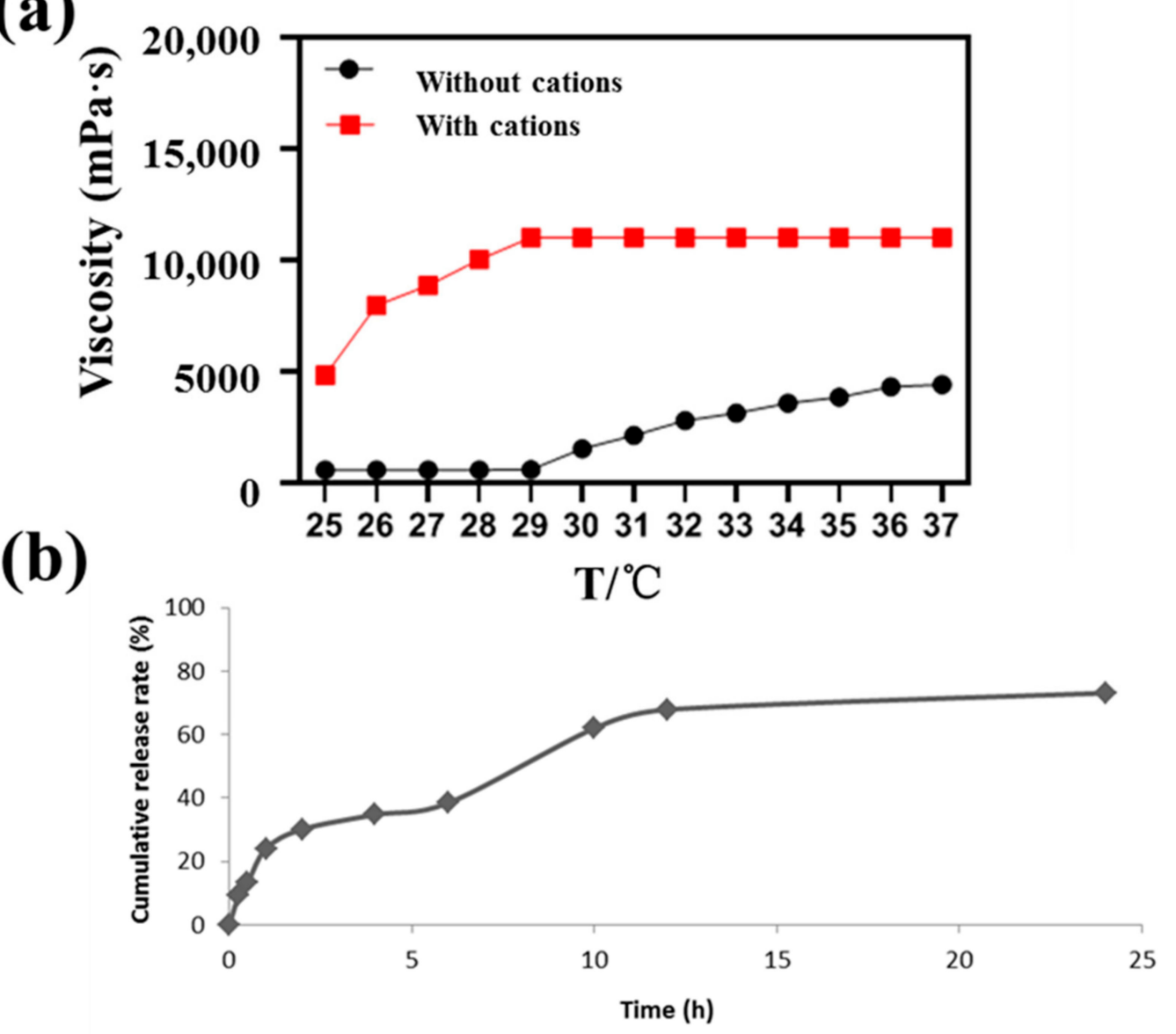

(c)

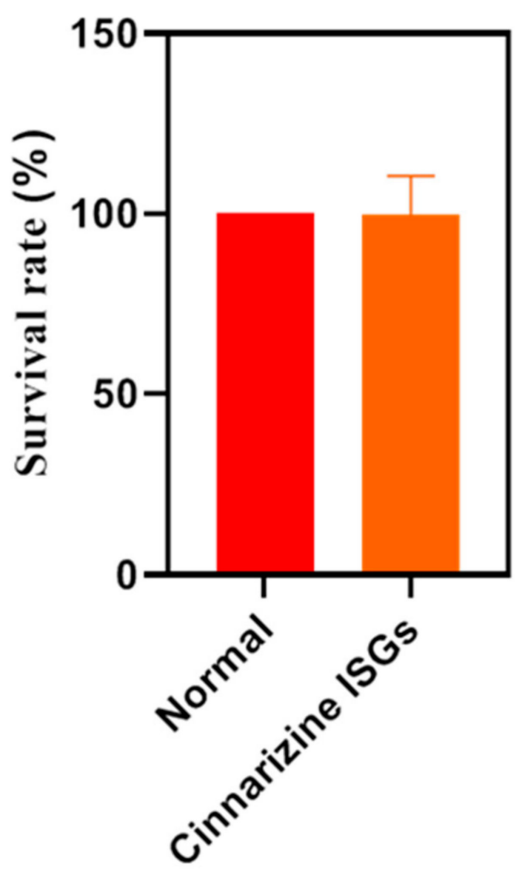

Figure 3. (a) Viscosity profiles of ISGs with temperature. (b) In vitro drug release profile of cinnarizine ISGs. (c) Survival rate of PC12 cells with cinnarizine ISGs. 


\subsection{Sustained Release and Cytotoxicity of Cinnarizine ISGs}

It is common knowledge that ISGs with hydrophilic three-dimensional networks formed by chemical or physical cross-linking can be regarded as the perfect substrate for controlling drug release. In this research, the cumulative release rate of cinnarizine from ISG within $12 \mathrm{~h}$ was $75 \%$, which was a slow-release process (Figure $3 \mathrm{~b}$ ). The mathematical simulation of the release curves suggested that the correlation coefficients of zero-order, first-order, and Higuchi equations were 0.770, 0.884, and 0.917. The release curve of cinnarizine from ISGs conformed to the Higuchi equation [33], indicating that the release mechanism of cinnarizine from ISGs was controlled by diffusion and matrix corrosion. This release mechanism of ISGs is preferred for facilitating long-term topical retention and release in the nasal cavity. Moreover, ISGs with SBE- $\beta$-CD might promote the cumulative permeation amount [34].

The survival rate of PC12 cells with cinnarizine ISGs was determined to evaluate the irritation (Figure 3c). This showed that cinnarizine ISGs were non-toxic to PC12 cells in $24 \mathrm{~h}$.

\subsection{High Brain Targeting of Intranasal Cinnarizine ISGs}

The in vivo process of intranasal cinnarizine ISGs and oral cinnarizine was compared. Intranasal cinnarizine ISGs had a $\mathrm{T}_{\max }$ of $0.9 \pm 0.2 \mathrm{~h}$ and a $C_{\max }$ of $304.2 \pm 58.5 \mathrm{ng} \cdot \mathrm{mL}^{-1}$, while p.o. had a $\mathrm{T}_{\max }$ of $1.5 \pm 0.44 \mathrm{~h}$ and a $\mathrm{C}_{\max }$ of $611.7 \pm 307.5 \mathrm{ng} \cdot \mathrm{mL}^{-1}$ (Table 1, Figure 4a). Although the bioavailability of intranasal cinnarizine ISGs was less than the oral route, they had higher drug content in the brain (Figure $4 b$ ).

Table 1. Brain targeting parameters of cinnarizine following intranasal and oral administration.

\begin{tabular}{cccccc}
\hline $\begin{array}{c}\text { Administration } \\
\text { Routes }\end{array}$ & Tissues & $\begin{array}{c}\mathbf{A U C}_{\mathbf{0 - 2 4}} \\
\left.\mathbf{( h *} \mathbf{n g} \cdot \mathbf{~ m L}^{-\mathbf{1}}\right)\end{array}$ & $\begin{array}{c}\mathbf{C}_{\mathbf{m a x}} \\
\mathbf{( n g} \cdot \mathbf{m L}^{-\mathbf{1}} \mathbf{)}\end{array}$ & $\begin{array}{c}\mathbf{T}_{\max } \\
\mathbf{( h )}\end{array}$ & $\begin{array}{c}\mathbf{A U C}_{\text {brain }} / \\
\mathbf{A U C}_{\text {blood }}\end{array}$ \\
\hline \multirow{2}{*}{ i.n. } & Blood & 3890 & 304.2 & 0.9 & 0.63 \\
& Brain & 2436 & 171.6 & 4 & \\
p.o. & Blood & 4945 & 611.7 & 1.5 & 0.19 \\
\hline
\end{tabular}

In this study, the brain targeting index (BTI, Equation (1)) was used to evaluate the brain targeting of the formulations. When the BTI value of formulations is greater than 1 , this indicates that the formulations have good brain targeting. The brain $C_{\max }$ of i.n. cinnarizine was much higher than that of i.v. cinnarizine (Figure $4 \mathrm{~b}$ ). The BTI of i.n. cinnarizine ISGs was 1.16 while the BTI of p.o. cinnarizine was only 0.35 , indicating the high brain targeting ability of i.n. cinnarizine.

Brain targeting index $(\mathrm{BTI})=($ AUCbrain/AUCblood $)$ i.n. $/$ p.o. $/($ AUCbrain $/$ AUCblood $)$ i.v

Brain targeting of the i.n. ISGs was confirmed by in vivo imaging. There was no fluorescence distribution of rhodamine B (RB) in the control group. The fluorescence of the p.o. group was concentrated in the stomach $30 \mathrm{~min}$ after administration, while the fluorescence of the i.n group was concentrated in the brain (Figure 4c) and then the fluorescence slowly spread to other parts of the body. After the organs were removed, we found that the fluorescence of the p.o. group was mainly concentrated in the stomach while the fluorescence of the i.n group was distributed in the brain and other organs (Figure 4d), which proved that intranasal administration could achieve brain targeting. It should be noted that $4 \mathrm{~h}$ after intranasal administration, the fluorescence of RB was also distributed in other organs, and especially in the stomach. This is because a small amount of RB gel can slowly enter the esophagus through the nasal cavity, reach the stomach, and spread to the whole body. 
(a)

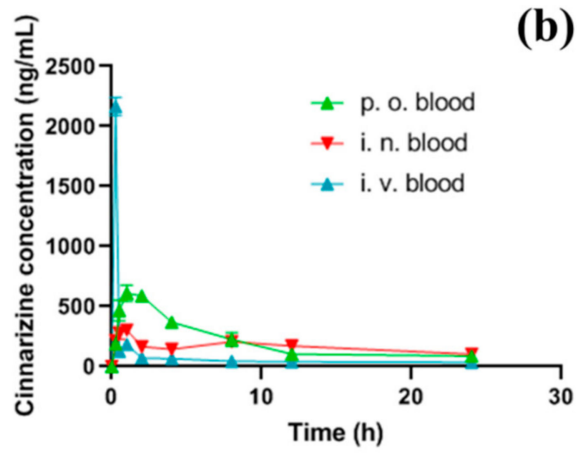

(c)

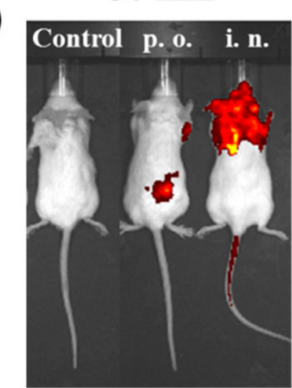

$60 \mathrm{~min}$

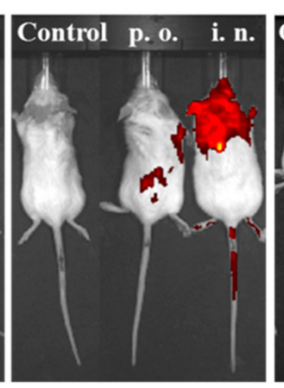

(b)

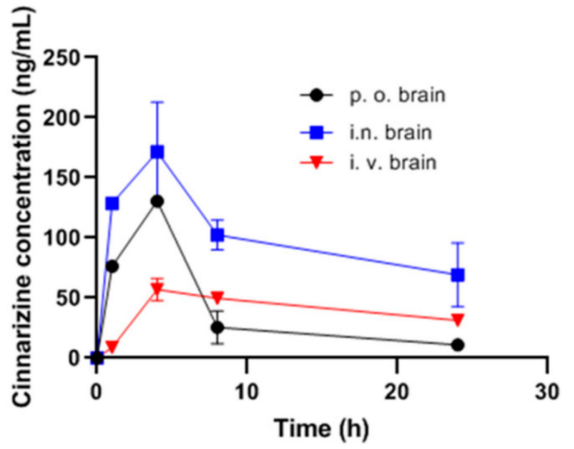

$120 \mathrm{~min}$

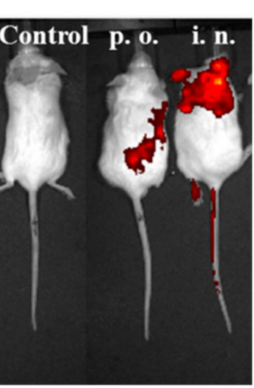

$240 \mathrm{~min}$

(d)

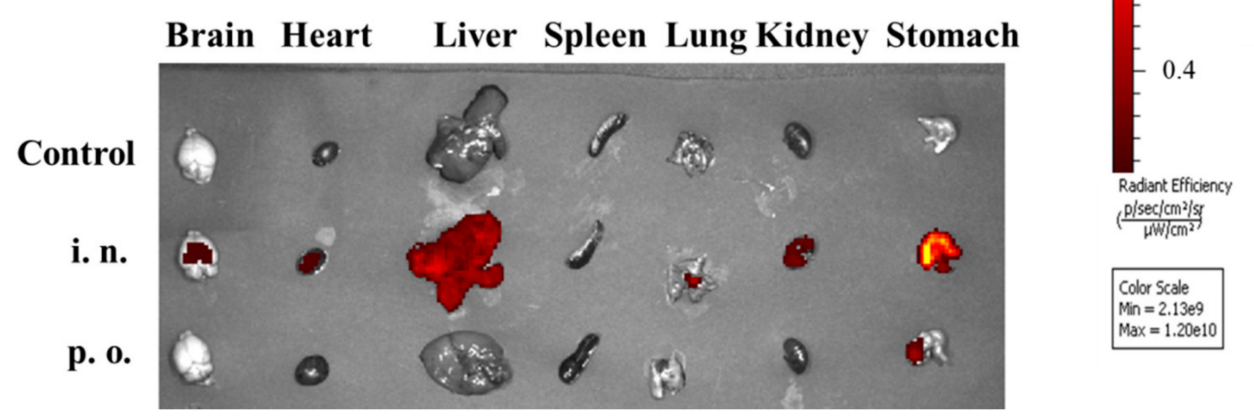

Figure 4. In vivo profiles of cinnarizine ISGs. (a) Cinnarizine formulations' concentration in the blood by p.o., i.n., and i.v. administration $(n=5)$; (b) its concentration in the brain after p.o., i.v., and i.n. administration $(n=3)$. (c) In vivo fluorescence imaging of mice with RB via oral or nasal route over time. (d) Fluorescence imaging of the major organs at $240 \mathrm{~min}$.

\subsection{Significant Therapeutic Effects of Cinnarizine ISGs on MIBI Rats}

2.5.1. Morris Water Maze to Detect the Spatial Memory of MIBI Rats

On the 3rd and 5th days after microwave irradiation, the average escape latency (AEL) of rats in the model group was significantly higher than that of the healthy group $(p<0.05)$. This showed that the spatial memory of rats exposed to microwaves had been affected and these rats needed to take more time to find the escape platform. Compared with the rats in the model group, intranasal cinnarizine ISGs decreased the AEL of rats on the 3rd and 5th days after microwave irradiation, indicating that intranasal cinnarizine ISGs improved the spatial memory ability of rats exposed to microwave $(p<0.05$, Figure $5 \mathrm{a})$. In addition, intranasal cinnarizine ISGs improved the spontaneous exploratory capability of rats exposed to microwave compared to that of the model group, which can be proved by the trace of space exploration trials of rats and the increase in the times of crossing the escape platform (Figure 5b,c). 
(a)

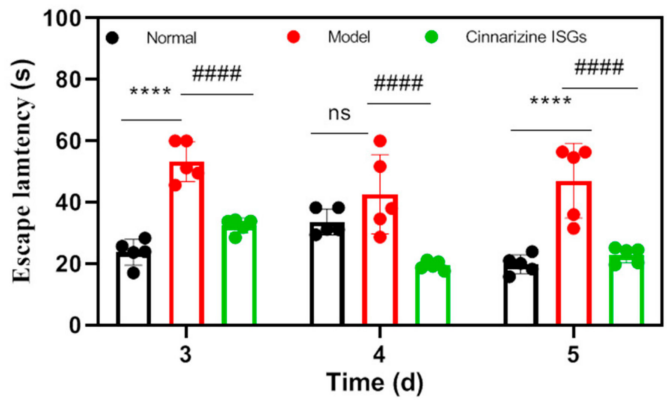

(c)

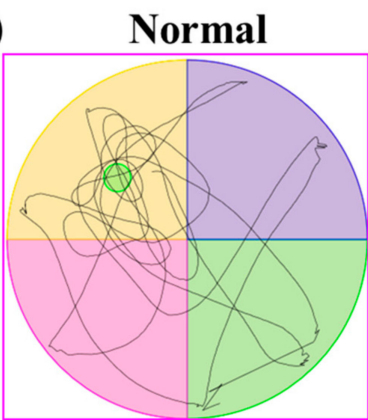

(b)

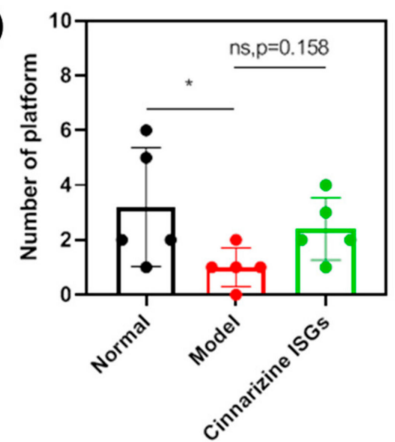

Cinnarizine ISGs

Figure 5. Average escape latency (a), number of platforms (b), and the trace map (c) of rats in the Morris water maze. $\left({ }^{*} p<0.05,{ }^{* * * *} p<0.001\right.$ vs. normal; \#\#\# $p<0.001$ vs. model.)

\subsubsection{Open Field Test to Evaluate the Spontaneous Behavior of MIBI Rats}

The total distance and the frequency of entering the central area were used as evaluating indicators to assess the spontaneous behavior of rats in the open field. The model rats displayed less spontaneous behavior than the healthy rats who were consistently moving in the surrounding area (Figure 6c).

(a)

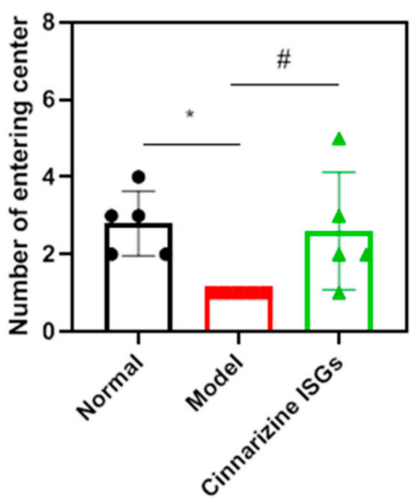

(c)

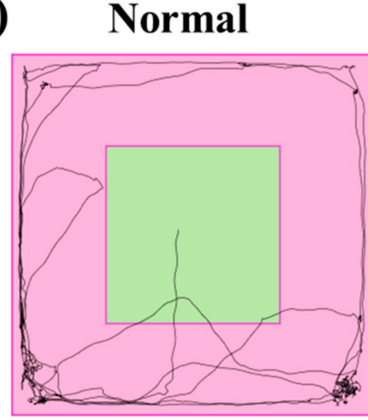

(b)

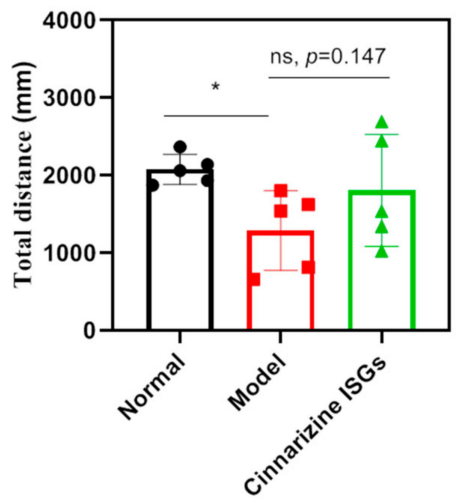

Cinnarizine ISGs
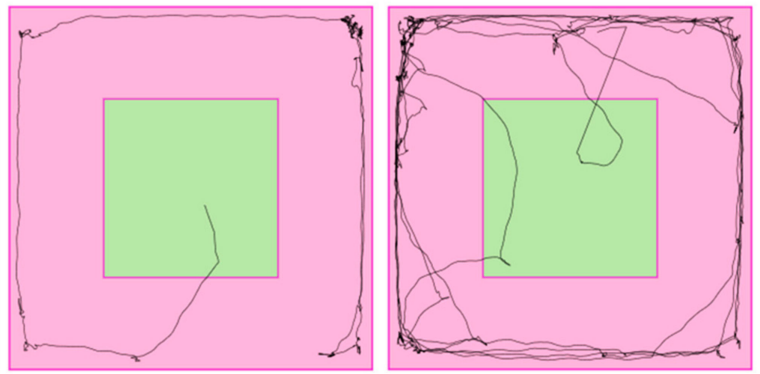

Figure 6. Number of times rats entered the central area (a), total distance (b), and the trace map (c) of rats in the open field. ( ${ }^{*} p<0.05$ vs. normal; $\# p<0.05$ vs. model.) 
The total distance $(p<0.05)$ and the number of times of entering the central area $(p<0.05)$ in the open field of MIBI rats were lower than those of the healthy group. The total distance and the number of times of entering the central area in the open field for the nasally administered cinnarizine ISGs groups $(p=0.147, p<0.05)$ increased compared with the rats in the model group (Figure $6 a, b$ ), which indicated that cinnarizine ISGs could effectively improve the spontaneous behavior and curiosity of MIBI rats.

\subsubsection{Pathological Evaluation of MIBI Rats Treated with Different Strategies}

The central nervous system (CNS) is sensitive to microwave irradiation, particularly the hippocampus $[35,36]$. After microwave irradiation, the cognitive function, learning, and memory of an organism associated with the hippocampus may be impaired [37]. Therefore, the hippocampus was the focus of our study of MIBI.

The pyramidal neurons in the dentate gyrus (DG) region of the hippocampus of rats in the healthy group were neatly arranged and had regular karyotypes. In contrast, the cells in the DG region of the hippocampus of the rats in the model group were sparsely arranged, and the karyotypes were irregular in shape (triangular or fusiform) (Figure 7a). In addition, the nuclei of neurons in the model group contracted and were deeply stained, suggesting that microwave radiation could cause neuronal cell necrosis in the DG area of the hippocampus. Compared with the model group, the neurons in the cinnarizine ISGs group had no nuclear shrinkage and deep staining, which indicated that the pathological changes in various brain regions of the rats induced by microwave irradiation were significantly alleviated after nasal administration of cinnarizine ISGs.

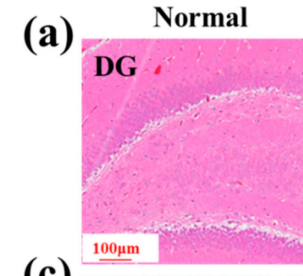

(c)

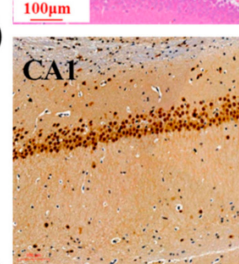

(e)

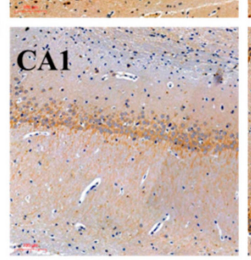

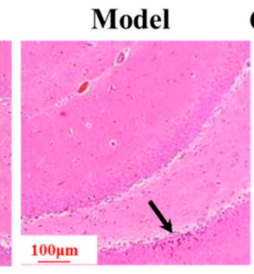
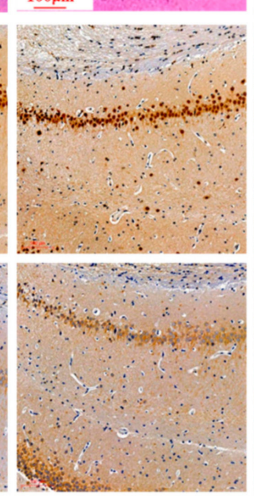
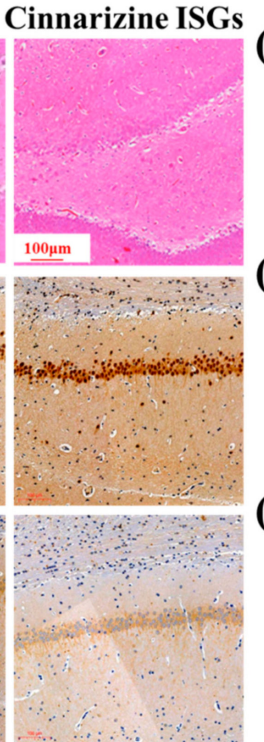

(b)

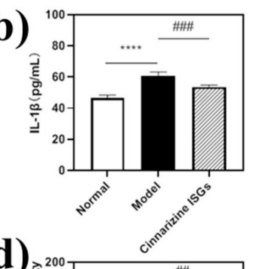

(d)

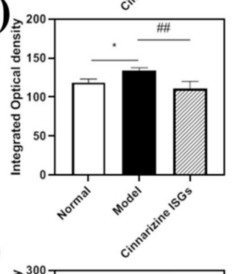

(f)

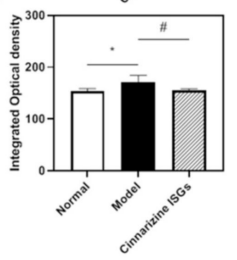

Figure 7. (a) H\&E staining of the DG of the hippocampus in rat brains (the black arrows represent the pyknosis and deep staining parts of neurons); (b) expression of IL- $1 \beta$ in the rat hippocampus; (c) CaN expression of the CA1 of the hippocampus in the rat brain, and the integrated optical density (IOD) of the CA1 of the hippocampus in the rat brain (d); (e) calpain-1 expression of the CA1 of the hippocampus in the rat brain, and the IOD of the CA1 of the hippocampus in the rat brain (f). (* $p<0.05,{ }^{* * * *} p<0.001$ vs. normal; \# $p<0.05$, \#\# $p<0.01$, \#\#\# $p=0.001$ vs. model.)

The mechanism of microwave radiation damage to the hippocampus is very complex, including oxidative damage, blood-brain barrier damage, and calcium overload. Among them, the calcium signaling pathway plays a key role in memory formation [38].

The expressions of calcineurin $(\mathrm{CaN})$ and calpain- 1 can be used as a sign of calcium overload by stimulation. Compared to the healthy group, the yellow staining in the hippocampal CA1 region of the model group deepened, indicating that the expressions of CaN and calpain-1 increased significantly (Figure 7c,e). After seven days of administration, 
cinnarizine ISGs could reduce the expressions of $\mathrm{CaN}$ and calpain-1 in the hippocampal CA1 region.

Image J v1.8.0 (National Institutes of Health, Bethesda, MD, USA) software was used to analyze the integrated optical density (IOD) of each region and each group in immunohistochemistry. Compared to the healthy group, the expressions of $\mathrm{CaN}$ and calpain- 1 in the CA1 area of the hippocampus in the model group were significantly unregulated $(p<0.05)$. However, cinnarizine ISGs $(p<0.05)$ could significantly reduce the expression of $\mathrm{CaN}$ and calpain- 1 in the CA1 area of the hippocampus compared to the model group (Figures $6 \mathrm{f}$ and $7 \mathrm{~d}$ ), which suggested that cinnarizine could treat microwave radiation brain injury by inhibiting calcium overload.

\subsubsection{Decreased Expression of IL-1 $\beta$ with Cinnarizine ISGs}

After microwave irradiation, the content of IL- $1 \beta$ in the brain tissue of the model group was significantly higher than that of the healthy group $(p<0.05)$. Compared with the model group, cinnarizine ISGs $(p<0.05)$ could significantly reduce the content of IL-1 $\beta$ in rat brain tissue (Figure $7 \mathrm{~b}$ ), which suggested that inflammation may be one of the pathogenic mechanisms of MIBI.

\subsection{Obvious Inhibitory Effects of Cinnarizine on Intracellular $\mathrm{Ca}^{2+}$ Content}

As shown in Figure 8a, undifferentiated PC12 cells were observed to be round, and the synapses of NGF-inducting cells were extended gradually from both ends of the cell body. The pictures of the cell culture medium after adding cinnarizine are shown in Figure $8 \mathrm{~b}$ and the cytotoxicity of PC12 cells with different concentrations of cinnarizine $(0,5,25,125$, $\left.25025 \mu \mathrm{g} \cdot \mathrm{mL}^{-1}\right)$ is shown in Figure 8c. After the addition of cinnarizine, the cell culture medium with $25 \mu \mathrm{g} \cdot \mathrm{mL}^{-1}$ cinnarizine was clarified. For the CCK-8 assay (Figure 8c), exposure to $500 \mu \mathrm{g} \cdot \mathrm{mL}^{-1}$ cinnarizine significantly decreased the cellular viability $(p<0.01)$, which was why $25 \mu \mathrm{g} \cdot \mathrm{mL}^{-1}$ cinnarizine was added to evaluate the intracellular $\mathrm{Ca}^{2+}$ concentration after microwave radiation. After microwave radiation, the intracellular $\mathrm{Ca}^{2+}$ content increased significantly $(p<0.01)$, and the intracellular $\mathrm{Ca}^{2+}$ content decreased to the normal level after $25 \mu \mathrm{g} \cdot \mathrm{mL}^{-1}$ cinnarizine was added (Figure $8 \mathrm{~d}, \mathrm{e}$ ).

(a)

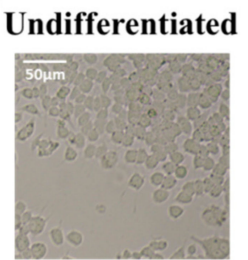

(c)

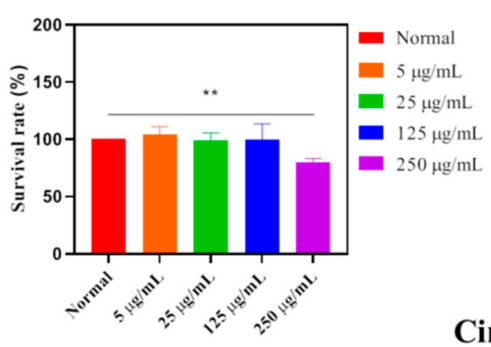

(b)

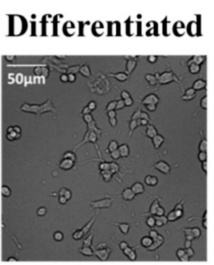

(d)
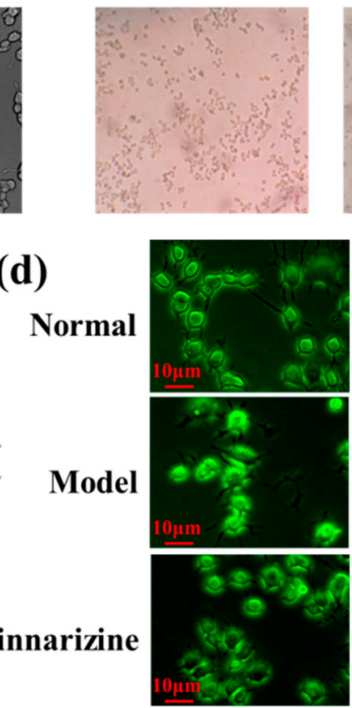

$125 \mu \mathrm{g} / \mathrm{mL}$

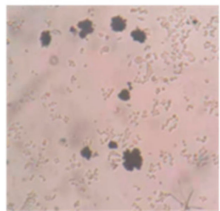

$250 \mu \mathrm{g} / \mathrm{mL}$

(e)

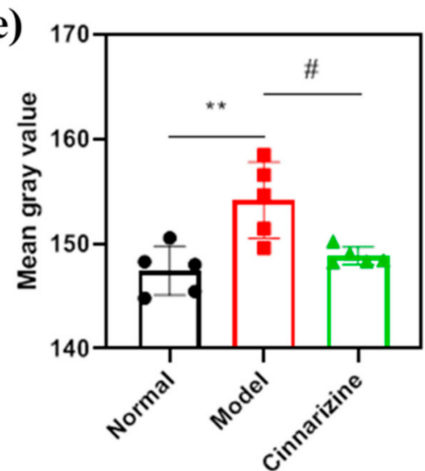

Figure 8. (a) Morphological changes in PC12 cells before and after differentiation $(20 \times)$; (b) cell culture medium with cinnarizine $(10 \times)$; (c) the cytotoxicity of PC12 cells with different concentrations of cinnarizine; (d) the pictures of PC12 cells with fluo-3; (e) the average fluorescence intensity of PC12 cells with fluo-3. (** $p<0.01$ vs. normal; $\# p<0.05$ vs. model.) 


\section{Conclusions}

Inclusion technology is highly mature. The inclusion complexes formed by cinnarizine and SBE- $\beta-C D$ significantly improved the solubility of the drug. ISGs are fluid liquids without outside stimuli but they become semi-solid gels under the influence of certain factors (such as temperature, $\mathrm{pH}$, and ions). The thermo- and ion-sensitive cinnarizine ISGs prepared in this study had appropriate gelation temperature, quick gelation, and enough viscosity. These advantages proved that thermo- and ion-sensitive ISGs can achieve long-term retention in the nasal cavity to achieve a sustained release, which are ideal formulations for nasal delivery. Cinnarizine is a promising drug against MIBI, which may be related to the reduction in calcium overload. Moreover, the intranasal administration of ISGs can achieve brain targeting.

\section{Materials and Methods}

\subsection{Materials}

The reagents used in this research are as follows: cinnarizine and SBE- $\beta-C D$ (Beijing Innochem Science \& Technology Co., Ltd., Beijing, China); P407 (Shanghai Yuanye BioTechnology Co., Ltd., Shanghai, China); DGG (Tianwei Biochemical Engineering Co., Ltd., Zhuji, China); purified water and deionized water were prepared by the Heal Force Super NW Water System (Shanghai Canrex Analytic Instrument Co., Ltd., Shanghai, China).

\subsection{HPLC Measurement}

Cinnarizine was detected by a high-efficiency liquid chromatography (HPLC) system (Agilent 1260 ) with a $\mathrm{C}_{18}$ column $(250 \mathrm{~mm} \times 4.6 \mathrm{~mm}, 5 \mu \mathrm{m})$. The composition of the mobile phase was methanol with the mixture of $0.2 \%$ triethanolamine and $0.04 \%$ trimethylamine $(\mathrm{pH}=6.6)$ at a ratio of 90:10 $(\mathrm{v} / \mathrm{v})$. Moreover, cinnarizine was detected at a detection wavelength of $254 \mathrm{~nm}$, a column temperature of $30^{\circ} \mathrm{C}$, a flow rate of $1.0 \mathrm{~mL} / \mathrm{min}$, and a sample size of $10 \mu \mathrm{L}$.

\subsection{Preparation of Cinnarizine Inclusion Complexes}

Two methods were used for the preparation of cinnarizine inclusion complexes [39].

Grinding method: Cinnarizine was mixed with SBE- $\beta-C D$ at mol ratios of 1:1, 1:2, and 1:3 in a mortar. A small amount of ethanol was added to the mortar to start one hour's grinding in the same direction and obtain a paste-like mixture that was dried at a constant $40{ }^{\circ} \mathrm{C}$ and ground properly to uniformity.

Freeze-drying method: An appropriate amount of cinnarizine raw material was dissolved in $10 \mathrm{~mL}$ ethanol while SBE- $\beta$-CD was dissolved in $10 \mathrm{~mL}$ deionized water. Cinnarizine solution and SBE- $\beta-C D$ solution were mixed at mol ratios of 1:1, 1:2, and 1:3 [40] and placed in a freeze dryer to be freeze-dried $42 \mathrm{~h} \mathrm{[39].}$

\subsection{Characterization of Cinnarizine Inclusion Complexes}

To study the inclusion rate of the inclusion complexes, the inclusion complexes prepared by the above methods were washed with ethanol three times (suction filtration) to remove free cinnarizine. After evaporation from light, they were dissolved in $10 \mathrm{~mL}$ of methanol and percolated with a $0.22 \mu \mathrm{m}$ microporous membrane. The filtrate was diluted by an appropriate multiple and entered into an HPLC to measure the content of cinnarizine. A formula for calculating the inclusion rate is shown in Equation (2) [41]:

Inclusion rate $(\%)=$ Cinnarizine in inclusion complexes $/$ Total Cinnarizine added $\times 100$

To study the solubility of the inclusion complex and cinnarizine in water, excessive cinnarizine and cinnarizine inclusion complex were added to deionized water and oscillated with $120 \mathrm{rpm}$ at $37^{\circ} \mathrm{C}$ for $7 \mathrm{~d}$. Meanwhile, excessive cinnarizine was added to $0,5,10,15$, 20,30 , and $50 \mathrm{mmol} / \mathrm{L}$ SBE- $\beta-\mathrm{CD}$ solutions and oscillated with $120 \mathrm{rpm}$ at $37^{\circ} \mathrm{C}$ for $3 \mathrm{~d}$. Then, the concentration of cinnarizine was detected by HPLC. A curve was drawn with 
the concentration of SBE- $\beta-\mathrm{CD}$ (X-axis) and the concentration of cinnarizine (Y-axis) to determine the type of inclusions.

An IR spectrogram of cinnarizine, SBE- $\beta-C D$, the cinnarizine/SBE- $\beta-C D$ inclusion complexes, and their physical mixture were obtained 3 times with a Fourier Transform Infrared Spectrometer (Spectrum TWO, Shanghai, China) [42] at $4000 \sim 600 \mathrm{~cm}^{-1}$, using the Attenuated Total Reflection (ATR) approach. Meanwhile, their compatibilities had been studied by DSC at 50 500 ${ }^{\circ} \mathrm{C}$ (TA DSC Q2000, New Castle, England) [43]. During the test, the heating rate of the instrument was $10{ }^{\circ} \mathrm{C} / \mathrm{min}$, and $\mathrm{N}_{2}$ was used as the protective gas.

\subsection{Preparation of Thermo- and Ion-Sensitive Cinnarizine ISGs}

ISGs were prepared by the physical mixing of P407 and DGG [44]. DGG was added into deionized water $(30 \mathrm{~mL})$ and fully swollen at $80^{\circ} \mathrm{C}$. After DGG solution cooling at $4{ }^{\circ} \mathrm{C}$, P407 and cinnarizine inclusion complexes were slowly added and mixed well. In order to obtain a pellucid solution, the resulting mixture was kept at $4{ }^{\circ} \mathrm{C}$ for $48 \mathrm{~h}$ and deionized water was added every $12 \mathrm{~h}$ to $50 \mathrm{~mL}$. Here, we optimized the contents of DGG and P407 in ISGs through an orthogonal experiment. A series of hydrogels with DGG concentrations of $0.1,0.2$, and $0.3 \%(w / v)$ and P407 concentrations of $16,17,18,20$, and $22 \%$ $(w / v)$ were prepared.

\subsection{Optimization and Characteristics of Cinnarizine ISGs}

The test tube inversion method was used to evaluate the gelation temperature of the ISGs. The ISGs were placed under a $20 \sim 40{ }^{\circ} \mathrm{C}$ water bath at a heating rate of $0.5^{\circ} \mathrm{C} / \mathrm{min}$ until ISGs' gelation.

Artificial nasal fluids (ANF) contain $150 \mathrm{mM} \mathrm{NaCl}, 40 \mathrm{mM} \mathrm{KCl}$, and $5 \mathrm{mM} \mathrm{CaCl}_{2}$, therefore the viscosity of ISGs containing $0.3 \%(w / v)$ DGG and $17 \%(w / v)$ P407 were determined at $25 \sim 37^{\circ} \mathrm{C}$ with or without cations by the viscometer (DV-III ULTRA, Sydney, Australia).

\subsection{In Vitro Release and Cytotoxicity of Cinnarizine ISGs}

The cinnarizine ISGs $\left(1 \mathrm{~mL}, 1 \mathrm{mg} \cdot \mathrm{mL}^{-1}\right.$ ) were put into a dialysis bag (cutting MW of $7000 \mathrm{Da}$ ) that was immersed in $20 \%$ ethanol solution of $50 \mathrm{~mL}$ and oscillated with $100 \mathrm{rpm}$ at $37^{\circ} \mathrm{C}$. At different time points of $0.5,1,2,4,8,12$, and $24 \mathrm{~h}, 1 \mathrm{~mL}$ of release medium pipetted was used for HPLC analysis and $1 \mathrm{~mL}$ of $20 \%$ ethanol solution at $37^{\circ} \mathrm{C}$ was immediately replenished [21,45]. There were three repeated experiments. The $20 \%$ ethanol solution was in line with the sink condition. The cumulative release rate $\left(\mathrm{Q}_{\mathrm{n}}\right)$ was calculated according to the following formula (3):

$$
\mathrm{Q}_{\mathrm{n}}=\frac{\mathrm{C}_{\mathrm{n}} \cdot \mathrm{V}+\mathrm{V}_{0} \sum_{\mathrm{i}=1}^{\mathrm{n}=1} \mathrm{C}_{\mathrm{i}}}{\mathrm{A}}
$$

where $\mathrm{V}(\mathrm{mL})$ was the volume of the release medium pipetted, $\mathrm{C}_{\mathrm{n}}\left(\mu \mathrm{g} \cdot \mathrm{mL}^{-1}\right)$ was the concentration of Sample $n, C_{i}\left(\mu g \cdot \mathrm{mL}^{-1}\right)$ was the concentration of Sample $i(i<n), V_{0}(m L)$ was the suction volume, and A ( $\mu \mathrm{g})$ was the drug content in the ISGs.

The drug release mechanism from ISGs was evaluated based on mathematical simulation models, inclusive of zero-order, first-order, and Higuchi equations. The equations were simulated by ELISA Calc (CSDN, Beijing, China). A high correlation coefficient (r) means a high correlation between simulated and real release mechanisms. The mathematical simulation model equations were listed as follows [46]:

(a) Zero-order model equation: $\mathrm{F}_{\mathrm{t}}=\mathrm{k}_{\mathrm{ro}} \mathrm{t}$

(b) First-order model equation: $\ln \left(1-\mathrm{F}_{\mathrm{t}}\right)=-\mathrm{k}_{\mathrm{r} 1} \mathrm{t}+\ln \mathrm{M}$

(c) Higuchi model equation: $\mathrm{F}_{\mathrm{t}}=\mathrm{k}_{\mathrm{H}} \mathrm{t}^{1 / 2}$

where $F_{t}(\%)$ was the cumulative release rate of the drug from ISGs for $t(h)$.

The harvested PC12 cells were suspended in $0.1 \mathrm{~mL}$ hydrogel with $25 \mu \mathrm{g} \cdot \mathrm{mL}^{-1}$ cinnarizine. The hydrogel was incubated at $37^{\circ} \mathrm{C}$ with $5 \% \mathrm{CO}_{2}$ in air for $24 \mathrm{~h}$. In total, $100 \mu \mathrm{L}$ of culture medium containing $10 \%$ CCK- 8 was added to each well. Then, the pore 
plate was placed in the cell incubator and incubated for $2 \mathrm{~h}$ in a humidified atmosphere of $5 \% \mathrm{CO}_{2}, 37^{\circ} \mathrm{C}$. After $2 \mathrm{~h}$, the absorbance was measured by the microplate reader at a wavelength of $450 \mathrm{~nm}$.

\subsection{Small Animal In Vivo Imaging}

BALB/c male mice ( $20 \pm 2 \mathrm{~g}$ ) were given $20 \mu \mathrm{L}$ of RB ISGs (4\%) by nasal cavity (i.n.) or $0.2 \mathrm{~mL}$ of RB solution $(0.4 \%)$ by gavage (p.o.), while the control group was not treated. After 30, 60, 120, and $240 \mathrm{~min}$, the small animal in vivo imaging system (IVIS Spectrum) was used to observe the fluorescence distribution in the small animals under the excitation wavelength of $535 \mathrm{~nm}$ and the emission wavelength of $580 \mathrm{~nm}$. Then, the mice were sacrificed by de-neck, and the heart, liver, spleen, lung, kidney, brain, and stomach were removed to observe the fluorescence distribution by IVIS Spectrum.

\subsection{In Vivo Pharmacokinetic Studies and Cinnarizine Distribution in the Brain}

Plasma and brain concentrations of cinnarizine were analyzed with an LC-MS/MS instrument that consisted of a $C_{18}$ column $(50 \mathrm{~mm} \times 3.0 \mathrm{~mm}, 2.6 \mu \mathrm{m}$, Phenomenex, Technologies, Thermo Fisher Scientific, Waltham, MA, USA) at $30{ }^{\circ} \mathrm{C}$. An LC system (LC-20AD, Shimadzu, Kyoto City, Kyoto Prefecture, Japan) coupled with a triple quadrupole MS/MS detector (API5000, AB Sciex, Framingham, MA, USA) was used. The mobile phase was composed of $0.1 \%$ formic acid aqueous solutions (A) and $0.1 \%$ formic acid acetonitrile solutions (B) at a flow rate of $0.6 \mathrm{~mL} / \mathrm{min}$ and an injection volume of $2 \mu \mathrm{L}$. The gradient elution was as follows: $10 \%$ B from 0.0 to $0.3 \mathrm{~min}, 10-90 \%$ B from 0.3 to $1.4 \mathrm{~min}, 90 \%$ B from 1.4 to $1.8 \mathrm{~min}, 90-10 \% \mathrm{~B}$ from 1.8 to $1.9 \mathrm{~min}$, and $10 \%$ B from 1.9 to $3.0 \mathrm{~min}$. The analysis was operated in the multiple reaction monitoring (MRM) mode, and its MS parameters are shown in Table 2.

Table 2. Multiple reaction monitoring (MRM) conditions.

\begin{tabular}{cccccccc}
\hline Name & $\mathbf{Q}_{\mathbf{1}}$ Mass $(\mathbf{D a})$ & $\mathbf{Q}_{\mathbf{3}}$ Mass $(\mathbf{D a})$ & Time (Msec) & DP (Volts) & EP (Volts) & CE (Volts) & CXP (Volts) \\
\hline Buspirone & 386.4 & 122.2 & 100 & 180 & 11 & 43 & 16 \\
Cinnarizine & 369.3 & 167.2 & 100 & 20 & 11 & 20 & 4 \\
\hline
\end{tabular}

Cinnarizine was dissolved in acetonitrile to prepare cinnarizine solutions at concentrations of $10,20,50,100,200,500,1000,2000,5000$, and $10,000 \mathrm{ng} \cdot \mathrm{mL}^{-1}$. The above cinnarizine samples $(5 \mu \mathrm{L})$ and the buspirone (Internal Standard, I.S.) in acetonitrile solution $\left(50 \mathrm{ng} \cdot \mathrm{mL}^{-1}, 1 \mathrm{~mL}\right)$ were added into the blank plasma or the blank brain of $45 \mu \mathrm{L}$ and homogenized with $0.9 \%$ saline $(1: 4, w / v)$ to obtain the final concentrations of $1,2,5$, $10,20,50,100,200,500$, and $1000 \mathrm{ng} \cdot \mathrm{mL}^{-1}$. Then, the mixture was vortexed for $1 \mathrm{~min}$ at room temperature and centrifuged with $14,000 \mathrm{rpm}$ for $10 \mathrm{~min}$ at $4{ }^{\circ} \mathrm{C}$. The plasma sample supernatant of $50 \mu \mathrm{L}$ diluted with $50 \%$ acetonitrile aqueous solution of $200 \mu \mathrm{L}$ and the brain homogenate sample supernatant of $20 \mu \mathrm{L}$ diluted with $50 \%$ acetonitrile of $180 \mu \mathrm{L}$ were used for analysis.

In the pharmacokinetics study, 45 rats were equally divided into 3 groups treated with the ISGs (i.n., $20 \mathrm{mg} / \mathrm{kg}$ ), intravenous (i.v., $2 \mathrm{mg} / \mathrm{kg}$ ), or oral (p.o., $20 \mathrm{mg} / \mathrm{kg}$ ), respectively. At $0,0.25,0.5,1,2,4,8,12$, and $24 \mathrm{~h}$, the rats' blood was taken $300 \mu \mathrm{L}$ from the tail vein and centrifuged at $4000 \mathrm{rpm}$ for $15 \mathrm{~min}$ at $4{ }^{\circ} \mathrm{C}$ to obtain plasma. At $1,4,8$, and $24 \mathrm{~h}$, the rats were sacrificed and the whole brain tissues were taken out. The buspirone (I.S.) in acetonitrile solution $\left(50 \mathrm{ng} \cdot \mathrm{mL}^{-1}, 0.6 \mathrm{~mL}\right)$ was added to the plasma and brain homogenate of $30 \mu \mathrm{L}$; then, the mixture was vortexed for $1 \mathrm{~min}$ at room temperature and centrifuged at $14,000 \mathrm{rpm}$ for $10 \mathrm{~min}$ at $4{ }^{\circ} \mathrm{C}$. The plasma supernatant of $50 \mu \mathrm{L}$ diluted with $50 \%$ acetonitrile aqueous solution of $200 \mu \mathrm{L}$ and the brain homogenate supernatant of $20 \mu \mathrm{L}$ diluted with $50 \%$ acetonitrile of $180 \mu \mathrm{L}$ were used for LC-MS/MS analysis. 


\subsection{Radiation Protection of Cinnarizine ISGs}

\subsubsection{Animals and Groups}

Male Wistar rats weighing 180 220 g were purchased from Beijing SPF Science \& Technology Co., Ltd., Beijing, China, which were of specific pathogen-free (SPF) grade and were maintained in an animal clean cabinet. All animal experimental procedures were conducted according to the guidelines of current laws and policies. The rats were divided into three groups with 8 rats in each group. Those radiated with $30 \mathrm{~mW} / \mathrm{cm}^{2}$ for $15 \mathrm{~min}$ but left untreated served as the model group [34]. Rats that were topically administrated with $100 \mu \mathrm{L}$ cinnarizine ISGs $\left(60 \mathrm{mg} \cdot \mathrm{mL}^{-1}, 60 \mathrm{mg} \cdot \mathrm{kg}^{-1} \cdot \mathrm{d}^{-1}\right.$, twice a day for seven consecutive days) by unilateral nasal cavity $1 \mathrm{~h}$ after radiation were referred to as the cinnarizine ISGs group. Those without radiation were classified as the control group (Figure 9).

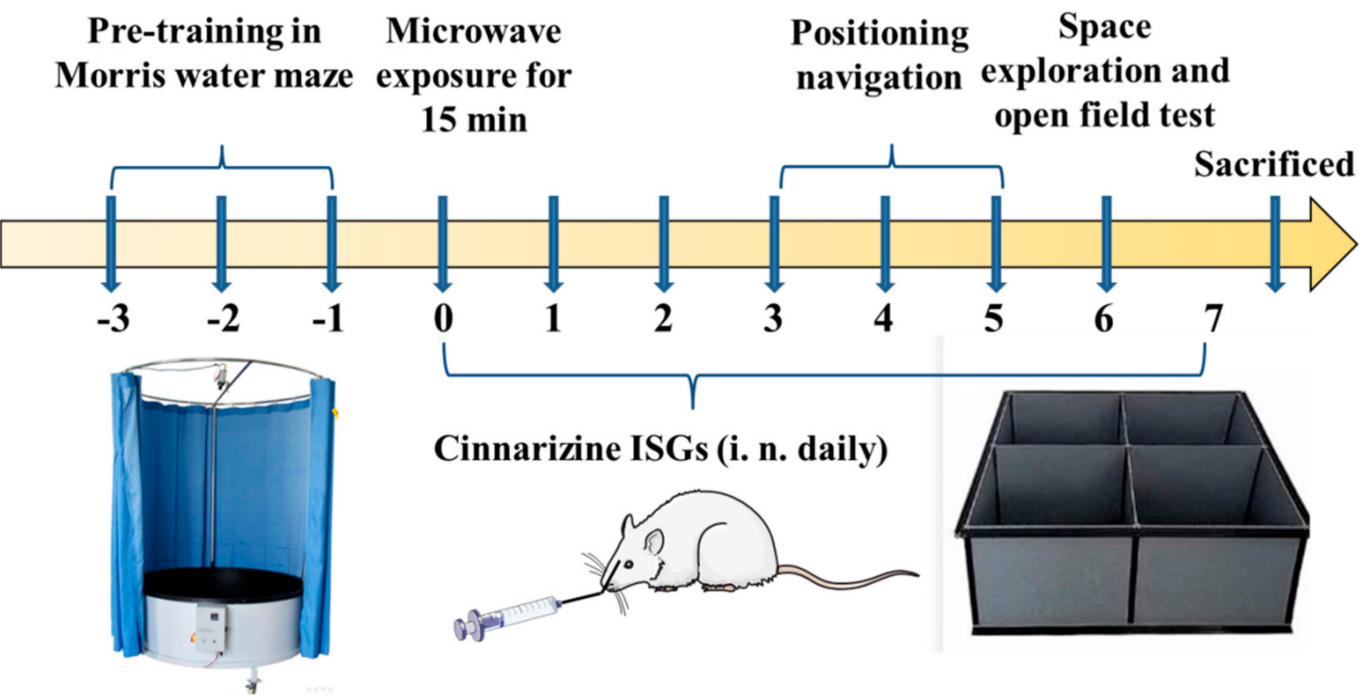

Figure 9. Scheme of pharmacodynamics study of cinnarizine ISGs.

\subsubsection{Morris Water Maze}

A Morris water maze (MWM) (ZS-001, Beijing, China), with $150 \mathrm{~cm}$ diameter and an escape platform of $8 \mathrm{~cm}$ diameter, was used to test the learning and memory abilities of rats via location navigation, and space exploring tests [47]. The depth of the water in MWM was $1.5 \mathrm{~cm}$ higher than the escape platform and the water temperature was maintained at $28 \pm 0.2{ }^{\circ} \mathrm{C}$. The water area was segmented into four quadrants (Quadrants I-IV) on average, with the escape platform at the center of Quadrant III. Each rat was separately lowered into the water at the middle edge of Quadrants I-IV. The movement traces of the rats were automatically traced by Labmaze V3.0 tracking system (Beijing Zhongshidichuang Science and Technology Development Co., Ltd., Beijing, China). During three days of training, the rats who climbed on the platform within $60 \mathrm{~s}$ were allowed to stay on the escape platform for $20 \mathrm{~s}$. If not, they were guided onto the escape platform and kept there for $20 \mathrm{~s}$. The location navigation trials of rats were similar to the above training process but without guidance and carried out on the $3 \mathrm{rd}, 4$ th, and 5 th days after i.n. administration of cinnarizine ISGs. The escape latency was defined as the time it took the rat to find the escape platform and kept there for more than $2 \mathrm{~s}$ after entering the water. If the rat failed to find the escape platform within $60 \mathrm{~s}$, the escape latency was recorded as $60 \mathrm{~s}$. The AEL of each rat was the average of the escape latency of the four quadrants.

The space exploration trials were carried out on the 6th day after i.n. administration of cinnarizine ISGs. The escape platform was removed, and the rats were placed into the water at the middle edge of the quadrant opposite that of the original escape platform. The number of times rats crossed the escape platform within $60 \mathrm{~s}$ was recorded. 


\subsubsection{Open Field Test}

The autonomous exploration behavior of the rats in a new environment was appraised by open field test (OFT) on the 6th day [48]. The open field (ZS-ZFT, Beijing Zhongshidichuang Science and Technology Development Co., Ltd., Beijing, China) was $100 \mathrm{~cm}$ long, $100 \mathrm{~cm}$ wide, and $50 \mathrm{~cm}$ high. All rats were put in the center of the open field on day 6 after administration of cinnarizine ISGs. The Labmaze V3.0 tracking system recorded the movement tracks of rats within $5 \mathrm{~min}$.

4.10.4. Pathological Observations and Expressions of IL-1 $\beta$, CaN, the Calpain-1 Receptor in MIBI Rats

After behavioral evaluation, the rats were sacrificed by neck removal and the brains of rats were immersed in $4 \%$ paraformaldehyde. The brain was sectioned for H\&E staining and $\mathrm{CaN}$ and calpain-1 immunohistochemistry. Hippocampal tissues of rats were peeled on ice. Hippocampal tissues/normal saline $(1: 9, w / v)$ were homogenized for $2 \mathrm{~min}$ and centrifuged at $4{ }^{\circ} \mathrm{C}$ at $1000 \times g$ for $10 \mathrm{~min}$ to obtain the supernatant by desktop freezing centrifuge (Fresco 21, Thermo Fisher Scientific Co., Ltd., Waltham, MA, USA). Then, the amount of IL- $1 \beta$ in the brain tissue was detected according to the instructions of the ELISA kit.

\subsection{The Mechanism Evaluation-The Influence of Cinnarizine on Intracellular $\mathrm{Ca}^{2+}$ Content 4.11.1. Cell Culture}

PC12 cells were cultured in RPMI-1640 (1640) medium supplemented with 1\% penicillinstreptomycin $(100 \times), 10 \%$ horse serum, and $5 \%$ fetal bovine serum in a humidified atmosphere at $37{ }^{\circ} \mathrm{C}, 5 \% \mathrm{CO}_{2}[49,50]$. PC12 cells were inoculated on a Petri dish pre-coated with $0.1 \mathrm{mg} \cdot \mathrm{mL}^{-1}$ poly-L-lysine (Sigma) at a density of $2.5 \times 10^{4}$ cells $/ \mathrm{cm}^{2}[51,52]$ and were differentiated into neuron-like cells with 1640 medium containing $1 \%$ horse serum and $50 \mathrm{ng} \cdot \mathrm{mL}^{-1}$ nerve growth factor NGF-2.5S (Sigma) [53,54]. Half of the medium was renewed every other day. Four to five days later, the PC12 cells were observed under the microscope to judge the degree of differentiation.

\subsubsection{Microwave Radiation and the Influence of Cinnarizine on Intracellular $\mathrm{Ca}^{2+}$ Content}

Differentiated PC12 cells were replaced with 1640 medium containing different concentrations of cinnarizine $\left(0,5,25,125\right.$, and $\left.250 \mu \mathrm{g} \cdot \mathrm{mL}^{-1}\right)$, and the cell survival was detected by CCK-8 assay [55] to choose a suitable concentration.

The differentiated PC12 cells were exposed to continuous microwave radiation for $15 \mathrm{~min}$ with an average power density of $30 \mathrm{~mW} / \mathrm{cm}^{2}$, and sham radiation control cells were treated under the same conditions without microwave exposure. The intracellular $\mathrm{Ca}^{2+}$ concentration was determined with a fluo-3/AM fluorescent probe, whose excitation wavelength was $488 \mathrm{~nm}$. After incubation with cinnarizine $\left(25 \mu \mathrm{g} \cdot \mathrm{mL}^{-1}\right)$, the PC12 cells were stained with fluo-3/AM $(5 \mu \mathrm{M})$ for $40 \mathrm{~min}$ and observed under a fluorescence microscope.

\subsection{Data Analysis}

The data were expressed as means \pm SD. Statistical differences between groups were analyzed with one-way ANOVA analysis of variance. All statistical analyses were performed by IBM $^{\circledR}$ SPSS $^{\circledR}$ Statistics software (Version 21). $p<0.05$ indicated significant statistical differences between groups.

Author Contributions: Y.Z. is the first author and was responsible for performing the surgical procedures, experiments, and data analyses. L.D. is leading investigator and the corresponding author of this study. Other authors (Q.L. (Qian Li), J.H., C.W., D.W., Q.L. (Qi Li), Q.J. and Y.J.) were partially involved in this study. All authors have read and agreed to the published version of the manuscript.

Funding: This research was funded by the Beijing Natural Science Foundation (7202147) and Natural Science Foundation of China (82172186). 
Institutional Review Board Statement: The animal study protocol was approved by the Animal Care Committee at Military Medical Research Institute (IACUC-DWZX-2020-532) and in compliance with the International Guidelines on Animal Care.

Informed Consent Statement: Not applicable.

Data Availability Statement: The data presented in this study are available on request from the corresponding author.

Conflicts of Interest: The authors declare that they have no known competing financial interests or personal relationships that could have appeared to influence the work reported in this paper.

\section{References}

1. Balduini, W.; Carloni, S.; Buonocore, G. Autophagy in hypoxia-ischemia induced brain injury. J. Matern.-Fetal Neonatal Med. 2012, 25 (Suppl. 1), 30-34. [CrossRef] [PubMed]

2. Gómez-Perretta, C.; Navarro, E.A.; Segura, J.; Portolés, M. Subjective symptoms related to GSM radiation from mobile phone base stations: A cross-sectional study. BMJ Open 2013, 3, e003836. [CrossRef] [PubMed]

3. Yakymenko, I.; Sidorik, E. Risks of carcinogenesis from electromagnetic radiation of mobile telephony devices. Exp. Oncol. 2010, 32, 54-60. [PubMed]

4. Anguera, M.; Gianini, R.J. Prevalence of fatigue reported by physiotherapists operating diathermy equipment for microwave. Rev. Bras. Epidemiol. 2014, 17, 577-581. [CrossRef]

5. Zhao, L.; Peng, R.Y.; Wang, S.M.; Wang, L.F.; Gao, Y.B.; Dong, J.; Li, X.; Su, Z.T. Relationship between cognition function and hippocampus structure after long-term microwave exposure. Biomed. Environ. Sci. 2012, 25, 182-188. [PubMed]

6. $\quad$ Dong, J.; Peng, R.Y.; Wang, S.M.; Gao, Y.B.; Wang, L.F.; Zhao, L. Effects on abilities of learning and memory and structural changes of brain in rats induced by microwave radiation under different conditions. Mil. Med. Sci. 2011, 35, 347-350.

7. Wang, B.; Lai, H. Acute exposure to pulsed 2450-MHz microwaves affects water-maze performance of rats. Bioelectromagnetics 2000, 21, 52-56. [CrossRef]

8. Wang, L.-F.; Li, X.; Gao, Y.-B.; Wang, S.-M.; Zhao, L.; Dong, J.; Yao, B.W.; Xu, X.P.; Chang, G.M.; Zhou, H.M.; et al. Activation of VEGF/Flk-1-ERK Pathway Induced Blood-Brain Barrier Injury after Microwave Exposure. Mol. Neurobiol. 2015, 52, 478-491. [CrossRef]

9. Wang, H.; Peng, R.; Zhou, H.; Wang, S.; Gao, Y.; Wang, L.; Yong, Z.; Zuo, H.; Zhao, L.; Dong, J.; et al. Impairment of long-term potentiation induction is essential for the disruption of spatial memory after microwave exposure. Int. J. Radiat. Biol. 2013, 89, 1100-1107. [CrossRef]

10. Lu, M.; Zhu, J.; Qian, C.; Wang, G.; Nie, J.; Tong, J. Biological effects of $2450 \mathrm{MHz}$ microwave combined with $\gamma$-rays on rat cultured gliacytes. J. Radiat. Res. Raidat. Process. 2010, 2010, 172-176.

11. Hu, S.; Peng, R.; Wang, C.; Wang, S.; Gao, Y.; Dong, J.; Zhou, H.; Su, Z.; Qiao, S.; Zhang, S.; et al. Neuroprotective effects of dietary supplement Kang-fu-ling against high-power microwave through antioxidant action. Food Funct. 2014, 5, 2243-2251. [CrossRef] [PubMed]

12. Hao, S.; Lv, H.; Wang, C.; Qi, X.; Tong, P.; Gou, Q. Effects of Anduolin on Caspase-9 and XIAP of testicular cells in rats irradiated by high-power microwave. J. Radiat. Res. Radiat. Process. 2016, 34, 6.

13. Tong, B.C.-K.; Wu, A.J.; Li, M.; Cheung, K.-H. Calcium signaling in Alzheimer's disease \& therapies. Biochim. Biophys. Acta Mol. Cell Res. 2018, 1865, 1745-1760. [PubMed]

14. Yang, R.; Peng, R.Y.; Gao, Y.B.; Wang, S.M.; Hu, W.H.; Xu, X.P. The effect of microwaves on hippocampal neurons in vitro and its mechanism. Phys. Med. Rehabil. 2006, 28, 670-673.

15. Abernethy, D.R.; Schwartz, J.B. Calcium-antagonist drugs. N. Engl. J. Med. 1999, 341, 1447-1457. [CrossRef]

16. Tokumura, T.; Tsushima, Y.; Tatsuishi, K.; Kayano, M.; Machida, Y.; Nagai, T. Evaluation of bioavailability upon oral administration of cinnarizine-beta-cyclodextrin inclusion complex to beagle dogs. Chem. Pharm. Bull. 1985, 33, 2962-2967. [CrossRef]

17. Gandhi, A.; Paul, A.; Sen, S.O.; Sen, K.K. Studies on thermoresponsive polymers: Phase behaviour, drug delivery and biomedical applications. Asian J. Pharm. Sci. 2015, 10, 99-107. [CrossRef]

18. Matanović, M.R.; Kristl, J.; Grabnar, P.A. Thermoresponsive polymers: Insights into decisive hydrogel characteristics, mechanisms of gelation, and promising biomedical applications. Int. J. Pharm. 2014, 472, 262-275. [CrossRef]

19. Teixeira, L.S.; Feijen, J.; van Blitterswijk, C.A.; Dijkstra, P.J.; Karperien, M. Enzyme-catalyzed crosslinkable hydrogels: Emerging strategies for tissue engineering. Biomaterials 2012, 33, 1281-1290. [CrossRef]

20. Sakakura, Y.; Majima, Y.; Yoshii, S.; Taniguchi, T.; Miyoshi, Y.; Ohyama, M. Nasal secretion from normal subjects. Auris Nasus Larynx 1979, 6, 71-78. [CrossRef]

21. Li, X.; Du, L.; Chen, X.; Ge, P.; Wang, Y.; Fu, Y.; Sun, H.; Jiang, Q.; Jin, Y. Nasal delivery of analgesic ketorolac tromethamine thermo- and ion-sensitive in situ hydrogels. Int. J. Pharm. 2015, 489, 252-260. [CrossRef] [PubMed]

22. Song, S.; Gao, K.; Niu, R.; Wang, J.; Zhang, J.; Gao, C.; Yang, B.; Liao, X. Inclusion complexes between chrysin and amino-appended $\beta$-cyclodextrins (ACDs): Binding behavior, water solubility, in vitro antioxidant activity and cytotoxicity. Mater. Sci. Eng. C Mater. Biol. Appl. 2020, 106, 110161. [CrossRef] [PubMed] 
23. Su, W.; Liang, Y.; Meng, Z.; Chen, X.; Lu, M.; Han, X.; Deng, X.; Zhang, Q.; Zhu, H.; Fu, T. Inhalation of Tetrandrine-hydroxypropyl$\beta$-cyclodextrin Inclusion Complexes for Pulmonary Fibrosis Treatment. Mol. Pharm. 2020, 17, 1596-1607. [CrossRef] [PubMed]

24. Yu, D.; Sun, C.; Zheng, Z.; Wang, X.; Chen, D.; Wu, H.; Wang, X.; Shi, F. Inner ear delivery of dexamethasone using injectable silk-polyethylene glycol (PEG) hydrogel. Int. J. Pharm. 2016, 503, 229-237. [CrossRef] [PubMed]

25. Wu, Y.; Wu, S.; Hou, L.; Wei, W.; Zhou, M.; Su, Z.; Wu, J.; Chen, W.; Ma, G. Novel thermal-sensitive hydrogel enhances both humoral and cell-mediated immune responses by intranasal vaccine delivery. Eur. J. Pharm. Biopharm. 2012, 81, 486-497. [CrossRef] [PubMed]

26. Mirza, M.A.; Ahmad, S.; Mallick, M.N.; Manzoor, N.; Talegaonkar, S.; Iqbal, Z. Development of a novel synergistic thermosensitive gel for vaginal candidiasis: An in vitro, in vivo evaluation. Colloids Surf. B Biointerfaces 2013, 103, 275-282. [CrossRef] [PubMed]

27. Yu, C.; Meng, J.; Chen, J.; Tang, X. Preparation of ergoloid mesylate submicron emulsions for enhancing nasal absorption and reducing nasal ciliotoxicity. Int. J. Pharm. 2009, 375, 16-21. [CrossRef]

28. Liu, Y.; Lu, W.-L.; Wang, J.-C.; Zhang, X.; Zhang, H.; Wang, X.-Q.; Zhou, T.-Y.; Zhang, Q. Controlled delivery of recombinant hirudin based on thermo-sensitive Pluronic F127 hydrogel for subcutaneous administration: In vitro and in vivo characterization. J. Control. Release 2007, 117, 387-395. [CrossRef]

29. Du, L.; Tong, L.; Jin, Y.; Jia, J.; Liu, Y.; Su, C.; Yu, S.; Li, X. A multifunctional in situ-forming hydrogel for wound healing. Wound Repair Regen. 2012, 20, 904-910. [CrossRef]

30. Al-Abd, A.M.; Hong, K.-Y.; Song, S.-C.; Kuh, H.-J. Pharmacokinetics of doxorubicin after intratumoral injection using a thermosensitive hydrogel in tumor-bearing mice. J. Control. Release 2010, 142, 101-107. [CrossRef]

31. Cai, Z.; Song, X.; Sun, F.; Yang, Z.; Hou, S.; Liu, Z. Formulation and evaluation of in situ gelling systems for intranasal administration of gastrodin. Aaps Pharmscitech 2011, 12, 1102-1109. [CrossRef] [PubMed]

32. Geethalakshmi, A.; Karki, R.; Kumar Jha, S.; P Venkatesh, D.; Nikunj, B. Sustained ocular delivery of brimonidine tartrate using ion activated in situ gelling system. Curr. Drug Deliv. 2012, 9, 197-204. [CrossRef] [PubMed]

33. Siepmann, J.; Peppas, N.A. Higuchi equation: Derivation, applications, use and misuse. Int. J. Pharm. 2011, 418, 6-12. [CrossRef]

34. Zhang, L.; Pang, L.; Zhu, S.; Ma, J.; Li, R.; Liu, Y.; Zhu, L.; Zhuang, X.; Zhi, W.; Yu, X.; et al. Intranasal tetrandrine temperaturesensitive in situ hydrogels for the treatment of microwave-induced brain injury. Int. J. Pharm. 2020, 583, 119384. [CrossRef] [PubMed]

35. Hao, Y.-H.; Zhao, L.; Peng, R.-Y. Effects of microwave radiation on brain energy metabolism and related mechanisms. Mil. Med. Res. 2015, 2, 4. [CrossRef] [PubMed]

36. Xiong, L.; Sun, C.F.; Zhang, J.; Gao, Y.B.; Wang, L.F.; Zuo, H.Y.; Wang, S.M.; Zhou, H.M.; Xu, X.P.; Ji, D.O.N.G.; et al. Microwave exposure impairs synaptic plasticity in the rat hippocampus and PC12 cells through over-activation of the NMDA receptor signaling pathway. Biomed. Environ. Sci. 2015, 28, 13-24. [PubMed]

37. Lu, Y.; Xu, S.; He, M.; Chen, C.; Zhang, L.; Liu, C.; Chu, F.; Yu, Z.; Zhou, Z.; Zhong, M. Glucose administration attenuates spatial memory deficits induced by chronic low-power-density microwave exposure. Physiol. Behav. 2012, 106, 631-637. [CrossRef] [PubMed]

38. Catterall, W.A.; Leal, K.; Nanou, E. Calcium channels and short-term synaptic plasticity. J. Biol. Chem. 2013, 288, 10742-10749. [CrossRef]

39. Pang, L.; Zhu, S.; Ma, J.; Zhu, L.; Liu, Y.; Ou, G.; Li, R.; Wang, Y.; Liang, Y.; Jin, X.; et al. Intranasal temperature-sensitive hydrogels of cannabidiol inclusion complex for the treatment of post-traumatic stress disorder. Acta Pharm. Sin. B 2021, 11, 2031-2047. [CrossRef]

40. Chunshom, N.; Chuysinuan, P.; Thanyacharoen, T.; Techasakul, S.; Ummartyotin, S. Development of gallic acid/cyclodextrin inclusion complex in freeze-dried bacterial cellulose and poly (vinyl alcohol) hydrogel: Controlled-release characteristic and antioxidant properties. Mater. Chem. Phys. 2019, 232, 294-300. [CrossRef]

41. Bittencourt, V.C.E.; dos Santos Moreira, A.M.; da Silva, J.G.; de Freitas Gomides, A.F.; Velloso-Rodrigues, C.; Kelmann, R.G.; Mendonça, L.M.; Lula, I.S.; Denadai, Â.M.L. Hydrophobic nanoprecipitates formed by benzoylphenylureas and $\beta$-cyclodextrin inclusion compounds: Synthesis, characterization and toxicity against aedes aegypti larvae. Heliyon 2019, 5, e02013. [CrossRef] [PubMed]

42. de Oliveira, C.X.; Ferreira, N.S.; Mota, G.V. A DFT study of infrared spectra and Monte Carlo predictions of the solvation shell of Praziquantel and $\beta$-cyclodextrin inclusion complex in liquid water. Spectrochim. Acta A Mol. Biomol. Spectrosc. 2016, 153, $102-107$. [CrossRef] [PubMed]

43. Yao, Q.; You, B.; Zhou, S.; Chen, M.; Wang, Y.; Li, W. Inclusion complexes of cypermethrin and permethrin with monochlorotriazinyl-beta-cyclodextrin: A combined spectroscopy, TG/DSC and DFT study. Spectrochim. Acta A Mol. Biomol. Spectrosc. 2014, 117, 576-586. [CrossRef] [PubMed]

44. Liu, Y.; Zhu, Y.-Y.; Wei, G.; Lu, W.-Y. Effect of carrageenan on poloxamer-based in situ gel for vaginal use: Improved in vitro and in vivo sustained-release properties. Eur. J. Pharm. Sci. 2009, 37, 306-312. [CrossRef]

45. Li, C.; Li, C.; Liu, Z.; Li, Q.; Yan, X.; Liu, Y.; Lu, W. Enhancement in bioavailability of ketorolac tromethamine via intranasal in situ hydrogel based on poloxamer 407 and carrageenan. Int. J. Pharm. 2014, 474, 123-133. [CrossRef]

46. Khan, S.; Trivedi, V.; Boateng, J. Functional physico-chemical, ex vivo permeation and cell viability characterization of omeprazole loaded buccal films for paediatric drug delivery. Int. J. Pharm. 2016, 500, 217-226. [CrossRef] 
47. Vorhees, C.V.; Williams, M.T. Morris water maze: Procedures for assessing spatial and related forms of learning and memory. Nat. Protoc. 2006, 1, 848-858. [CrossRef]

48. Fan, X.-W.; Liu, H.-H.; Wang, H.-B.; Chen, F.; Yang, Y.; Chen, Y.; Guan, S.-K.; Wu, K.-L. Electroacupuncture Improves Cognitive Function and Hippocampal Neurogenesis after Brain Irradiation. Radiat. Res. 2017, 187, 672-681. [CrossRef]

49. Liu, Z.; Ko, C.H.; Ng, C.F.; Wong, H.L.; Zhang, J.F.; Lam, P.K.; Poon, W.S.; Leung, P.C. Antioxidative effect of Gastrodiae Rhizoma-containing herbal formula in PC12 cell model: Abridged secondary publication. Hong Kong Med. J. 2020, 26 (Suppl. 6), $44-46$.

50. Hu, R.; Cao, Q.; Sun, Z.; Chen, J.; Zheng, Q.; Xiao, F. A novel method of neural differentiation of PC12 cells by using Opti-MEM as a basic induction medium. Int. J. Mol. Med. 2018, 41, 195-201. [CrossRef]

51. Zuo, H.; Lin, T.; Wang, D.; Peng, R.; Wang, S.; Gao, Y.; Xu, X.; Li, Y.; Wang, S.; Zhao, L.; et al. Neural cell apoptosis induced by microwave exposure through mitochondria-dependent caspase-3 pathway. Int. J. Med. Sci. 2014, 11, 426-435. [CrossRef] [PubMed]

52. Zuo, H.; Lin, T.; Wang, D.; Peng, R.; Wang, S.; Gao, Y.; Xu, X.; Zhao, L.; Wang, S.; Su, Z. RKIP Regulates Neural Cell Apoptosis Induced by Exposure to Microwave Radiation Partly through the MEK/ERK/CREB Pathway. Mol. Neurobiol. 2015, 51, 1520-1529. [CrossRef] [PubMed]

53. Katebi, S.; Esmaeili, A.; Ghaedi, K.; Zarrabi, A. Superparamagnetic iron oxide nanoparticles combined with NGF and quercetin promote neuronal branching morphogenesis of PC12 cells. Int. J. Nanomed. 2019, 14, 2157-2169. [CrossRef] [PubMed]

54. Strachan-Whaley, M.R.; Reilly, K.; Dobson, J.; Kalisch, B.E. Map kinase and PKC signaling pathways modulate NGF-mediated apoE transcription. Neurosci. Lett. 2015, 595, 54-59. [CrossRef] [PubMed]

55. Cai, L.; Qin, X.; Xu, Z.; Song, Y.; Jiang, H.; Wu, Y.; Ruan, H.; Chen, J. Comparison of Cytotoxicity Evaluation of Anticancer Drugs between Real-Time Cell Analysis and CCK-8 Method. ACS Omega 2019, 4, 12036-12042. [CrossRef] [PubMed] 